\title{
A public value based method to select services for a no-stop shop implementation
}

\author{
Hendrik Scholta \\ University of Muenster - ERCIS \\ hendrik.scholta@ercis.uni- \\ muenster.de
}

\author{
Sebastian Halsbenning \\ University of Muenster - ERCIS \\ sebastian.halsbenning@ercis.uni- \\ muenster.de
}

\author{
Jörg Becker \\ University of Muenster - ERCIS \\ joerg.becker@ercis.uni- \\ muenster.de
}

\begin{abstract}
Nowadays, public organizations become proactive in their service delivery such that they approach their clients and not vice versa. In the most advanced case, the no-stop shop, clients do not have to do anything to receive a public service. Public organizations offer many services and several of them could potentially be delivered through a no-stop shop. Therefore, public organizations need assistance in the decision which services they realize in a no-stop shop first. To address this issue, we present a method for the prioritization of public services for the implementation in a no-stop shop. The rationale of our method is that public organizations should prefer those services that are expected to provide the highest public value. We followed a design-oriented research approach and combined seminal works on nostop shop and public value. The method was evaluated through the application in a workshop at a municipality.
\end{abstract}

\section{Introduction}

The digitization of the public sector continues to advance and public organizations are increasingly encouraged to provide their services as conveniently as possible for clients (citizens and businesses) [1] Today's clients expect public organizations to be innovative and digital solutions are already an essential part of public service offerings in many countries [2]. In their striving for innovation, public organizations look for new ways to increase the clients' convenience. In the simplest and most convenient way, clients do not have to do anything to receive a public service which results in a no-stop shop [3]. In a no-stop shop, public organizations provide services proactively without any activity on the part of clients. By analyzing clients' data, public organizations anticipate their needs and do not need to rely on applications to initiate the service delivery process. For a no-stop shop, the clients' data needs to be collected and integrated such that public services no longer have to be requested by clients, but are provided by the public organizations without request.

Although there are some examples of a no-stop shop in practice such as in Austria [4] and Norway [5], there is much more potential for public organizations to turn their services from reactive delivery to proactive delivery in a no-stop shop. There are many services such as family allowance and tax return [3] that can potentially be implemented in a no-stop shop and delivered without application, and public organizations have to decide which services they realize in a no-stop shop first. Since public organizations have limited financial and human resources, not all services can be offered immediately in a no-stop shop. Instead, public organizations have to prioritize their services for a nostop shop implementation and a step-by-step conversion of services is recommended.

The decision to realize a service in a no-stop shop is a specific digitalization decision since it fundamentally changes the relationship between public organization and client. Whereas in conventional reactive service delivery, the client must approach the organization, in proactive delivery in a no-stop shop the public organization approaches the client and provides a service without their explicit consent. The term nostop shop is chosen since a public organization delivers a service with no client action and, thus, there is "no stop" for the client. A no-stop shop might overcome situations where clients feel like a supplicant since they need to ask the public organization for a service [6]. As public organizations deliver services without asking their clients for consent, a no-stop shop can also be negative if it is perceived as dictation [7]. Due to this fundamental shift in the client-to-government relationship, the selection of services for a no-stop shop is not an easy decision and dedicated instruments are necessary that assist public organizations in making this decision.

In order to provide public organizations with such an instrument, we address the following research goal: Design of a method for the prioritization of public 
services for the implementation in a no-stop shop. Based on the prioritization of services obtained by the application of our method, practitioners can decide to implement the services with the highest priorities at first in a no-stop shop. Thus, we aim to support public organizations in selecting services for a no-stop shop. Our method is intended to be applicable to public organizations in general and is not dedicated to a certain organization and its characteristics. The design of the method is independent of organization-specific details but addresses public organizations worldwide.

In order to be widely applicable, our method bases on the public value concept [8], [9], which considers benefits for different stakeholders, e.g. for public organizations internally, for their clients externally and relational benefits [10]. The rationale of our method is that public organizations should select those services first that are estimated to provide the highest value for the society, i.e. the highest public value. The overall prioritization of services for the no-stop shop is determined by aggregating the services' estimated effects on different criteria and dimensions of public value.

Our paper is structured as follows. In section two, we present relevant background for our work on no-stop shop and public value. Subsequently, we explain details of our research design in section three. The core section of our paper is section four where we present our method for the selection of services for a no-stop shop implementation. We elaborate on our method's evaluation in section five and conclude in section six.

\section{Research Background}

\subsection{No-Stop Shop}

Incorporating proactive actions of public organizations into public service delivery has been called as a shift from the "pull" to the "push" paradigm [11]. For proactivity, it is essential that the public organization "approaches the recipient before the recipient contacts the public sector organization." [7, p. 3] Such proactive actions cover, for instance, recommendations of services that might be relevant to a client [12], [13]. The no-stop shop [3], [14], also known as no-stop government [12], is the most extreme manifestation of proactivity. In a no-stop shop, a client does not have to perform any action to obtain a public service.

One example of such a no-stop shop is the provision of family allowance in Austria [15]. The hospital informs the responsible registration authority after the birth of a child. The necessary data is then integrated at the central registry of the Federal Ministry of the Interior and forwarded to the Federal Ministry of Finance. The data is then transferred to the responsible tax office, which decides whether to grant family allowance and then informs the client. The client only needs to notice that they will receive family allowance from now on.

Recent work on proactivity and the no-stop shop deals with challenges and enablers and provides design recommendations for such implementations. When public organizations become proactive in their services, they should ask clients for information only once (onceonly principle [16], [17]), provide clients the opportunity to opt-out, be transparent about their data use and secure client data [18], [19]. Typical challenges and according actions that need to be undertaken to address these challenges are conducting required legal adaptions, adhering to privacy regulations and establishing inter-organizational cooperation and interoperability [20]. A solid foundation with functioning IT systems, the use of mobile technologies and capabilities for big data analytics can facilitate and enable proactivity in public services [11].

A no-stop shop can affect the quality of public services positively and negatively [21]. A no-stop shop can be useful if it releases clients from avoidable actions such as filling application forms. However, a no-stop shop can also be problematic especially if it does not cover all clients and the neediest clients have to care about obtaining a service themselves [5].

Still, there is potential for further research on how to implement no-stop services. We would like to take a first step towards it by addressing a preliminary question: Which services should a public organization implement in a no-stop shop? We provide a method that helps a public organization to answer this question for its individual case. The method is based on the public value concept.

\subsection{Public Value}

The assessment of public service delivery goes beyond pure economic measures given, for instance, the societal impact of public services. The necessity to take special measurement approaches for the outcomes of public organizations stems from the principal viewpoint that the public sector takes a fundamentally different function in economy and society than the private sector. Based on this recognition, the public value approach was introduced as a target and evaluation basis to assess a public organization's outcome [9].

Public value describes the public sector's contribution to society [8]. Despite this rather generic definition, the public value is used as a suitable benchmark for assessing public service delivery [22] and also its digitalization [23]. This approach indicates a shift from the narrow assessment of single IT investments or the IS success towards a broader view on 
the societal impact of the whole service delivery process [24]. Classical measures to rate digitalization efforts merely comprise internal measures focusing on the (monetary) value of IT for public organizations, such as return on investments [25], or net benefits focusing on the external/the client perspective [24].

In the light of the public value, these classical approaches insufficiently incorporate other categories of public service values. Digital government endeavors, however, need to be assessed by a multidimensional perspective [26], [27]. More specifically, the public value of digital government comprises the six dimensions "improved public services; improved administrative efficiency; Open Government (OG) capabilities; improved ethical behavior and professionalism; improved trust and confidence in government; and improved social value and well-being" [10, p. 170].

The suitability of the public value concept to rate digital government success has already been proven [28]. But for the ongoing digitalization of the public sector and especially the ex-ante selection of services for a no-stop shop, an ex-post success measurement is not sufficient. Here, the public value concept is applicable to decision-making in the public sector since it considers the relevant perspectives (internal, external and relational) and dimensions of public services for balanced decisions. In this paper, we understand proactive service delivery in a no-stop shop as a subset of digital government as used by Twizeyimana and Andersson [10]. We argue that their established set of key performance indicators (KPIs) is suitable for decisions on which services to implement in a no-stop shop since there is a need for a stronger recognition of performance indicators in the public sector [29].

\section{Research Design}

Since we aim to propose a method for the prioritization of public services for the no-stop shop, we followed the design science research (DSR) paradigm that is dedicated to the development of IT artifacts, and methods are one kind of IT artifacts [30]. In our research, we have applied the DSR activities suggested by Österle et al. [31]: analysis, design, evaluation and diffusion.

In the analysis activity, we detected the research gap to be addressed and sharpened our domain understanding. Based on the literature and practical examples outlined in sections 1 and 2, we identified the need for our method and obtained knowledge in the research areas of proactive public services, no-stop shop and public value.

In the design activity, we developed our method. We started by conceptually relating two scientific works. Since we intended to propose a method that compares the contributions and downsides of turning reactive services into no-stop shop services, we were looking for research that tells us what these contributions could be. We decided to build on the work from Twizeyimana and Andersson [10] on public value since it proposes dimensions that could be affected by the digitalization of public organizations and considers various stakeholders in the entire society.

Since the work from Twizeyimana and Andersson [10] targets digital government initiatives in general but not no-stop shop in particular, we were looking for research that indicates changes evoked by a conversion into no-stop shop delivery. We selected the work from Scholta and Lindgren [7] as the second foundation for our method since it depicts changes in the delivery of digital public services resulting from proactivity and nostop shop.

We related and matched these two works from Twizeyimana and Andersson [10] and Scholta and Lindgren [7] to come up with criteria that indicate changes in public value [10] caused by a no-stop shop implementation [7]. Twizeyimana and Andersson [10] provide a list of KPIs for six dimensions of the public value of digital government. By combining this list with the work from Scholta and Lindgren [7], we identified relevant dimensions and indicators that can be affected by the no-stop shop. We were able to transfer the KPIs into criteria dedicated to the no-stop shop by merging, splitting, extending, detailing, removing, and adding indicators.

Later on, through discussions in our research group and interviews with practitioners, we refined these criteria and developed a method to specify how to apply them. We conducted two semi-structured interviews with public officials to assess the six public value dimensions by Twizeyimana and Andersson [10] for their applicability to indicate the value of public services and the implementation in a no-stop shop. The questions aimed at general insights regarding decision drivers for service digitalization and the relevance of the six public value dimensions and their criteria for the decision about the implementation in a no-stop shop. We selected a manager for customer experience from a ministry of transport and a principal investigator from a treasury ministry both from the state level of government as interviewees. The interviews lasted 37 minutes on average, were recorded, transcribed and analyzed according to our research goal.

After the design activity, we assessed the appropriateness of our method in the evaluation activity. For this purpose, we applied our method to real-world services of a German municipality in a workshop with employees from this public organization. The threehour workshop was attended by five managerial and 


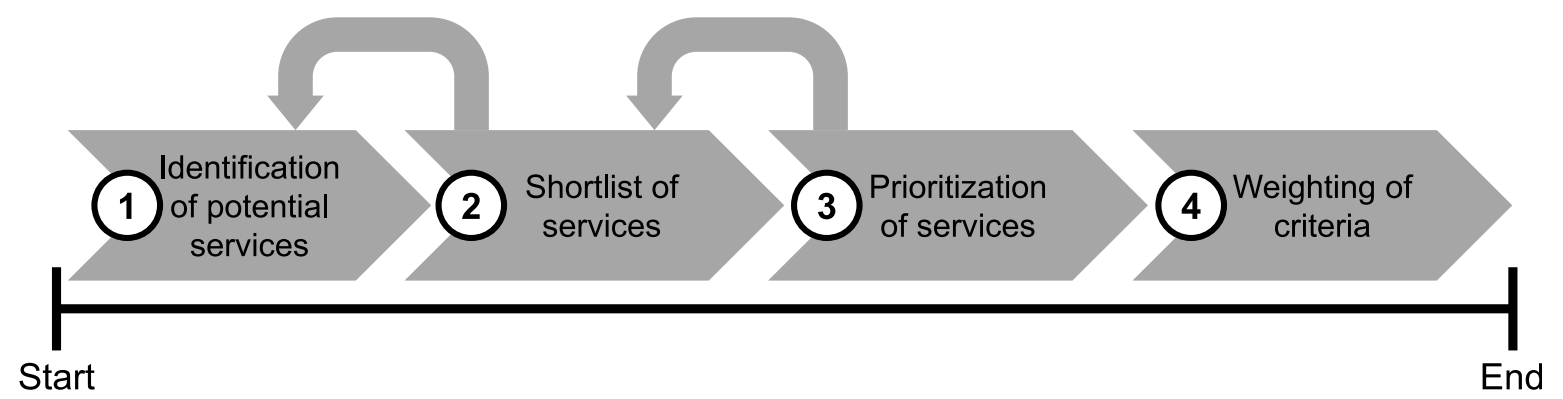

Figure 1. Steps of the method to select services for a no-stop shop

professional employees from the citizen services, security services and labor and social affairs departments. Due to this variety of participants, we were able to cover and discuss a wide range of public services. The workshop was recorded, transcribed and qualitatively analyzed.

The workshop consisted of three phases. First, we performed an introduction to explain the no-stop shop concept and the aims of our method and the workshop. Second, we applied the steps of our method to services of the municipality. The participants assessed their services to come up with a decision which services could be implemented first in a no-stop shop. Third, we asked for general feedback and suggestions for improvement of our method. We used the results of the workshop to revise our method.

In the diffusion activity, we disseminate our results through scientific presentations and publications such as this paper.

\section{A Method to Select Services for a No- Stop Shop}

\subsection{Design}

The way public services are provided impacts many areas of clients' lives directly or indirectly, the public organization itself and the society as a whole. To capture these affected areas as completely as possible, the scientifically established framework of KPIs by Twizeyimana and Andersson [10] was selected as the basis for the method, since these KPIs were explicitly developed for assessing the public value of digital government. This set of KPIs was the starting point for the development of our method, which supports the prioritization of services for a no-stop shop. The basic idea is that a proactive provision of different services also has a different impact on the respective criteria and, thus, provides different levels of benefit (public value) for the stakeholders. We selected the criteria of five dimensions [10] that are relevant for a no-stop shop and adapted them for the purpose of the method based on the work from Scholta and Lindgren [7], discussions and interview results. We excluded the dimension open government capabilities since the practitioners argued that this dimension would not affect the service delivery process in a no-stop shop. One interviewee exemplarily argued that he cannot imagine how to realize that, since the public organization approaches the client only in one direction. The interviewees did not question the importance of the dimension for enhancing participation and transparency in general as summarized by one interviewee: "We should [...] increase engagement with our citizens and get them to participate." However, the nature of no-stop shops counteracts the goals of open government, as no-stop shops aim to reduce client involvement instead of increasing it [3]. The criteria of the remaining five dimensions were contextualized with reference to proactive service provision in a no-stop shop (cf. Table 1). Criteria were added, supplemented, refined, summarized or removed.

When looking at the criteria, it becomes clear that their operationalization would be very complex in many cases. Thus, an exact quantification ex ante, for example in terms of estimated time or cost savings, is difficult. Not every benefit can be quantified easily in terms of time and money, e.g., the impact of a no-stop shop on the social cohesion of a society. The different indicators are therefore difficult to measure on a common monetary or temporal scale and are not comparable. For this reason, we chose an approach for the method that aims at a subjective comparison between the services under investigation.

The method can be divided into four steps (cf. Figure 1), which do not have to be executed in a strict sequential order but allow for returns to prior steps. Furthermore, it is particularly useful to carry out the method with a group of people (e.g., in a workshop) in order to include different perspectives in the decisionmaking process. This is important to reduce individual influences and to have broad expertise available. The actual execution mode is up to the requirements of the respective public organization. For example, workshop formats with employees from different departments or with the involvement of clients are possible. 
Table 1. Criteria of the method and their rationales

\begin{tabular}{|c|c|c|c|}
\hline Category & $\#$ & $\begin{array}{l}\text { Criterion: } \\
\text { Proactive delivery of public services in a no-stop shop... }\end{array}$ & $\begin{array}{l}\text { Rationale: } \\
\text { A proactive delivery in a no-stop shop leads to a change regarding this criterion since... }\end{array}$ \\
\hline \multirow{5}{*}{$\begin{array}{l}\text { Improved } \\
\text { public services }\end{array}$} & $1 \mathrm{~A}$ & leads to an easier receipt of a public service. & clients no longer have to take an action or submit an application. \\
\hline & $1 \mathrm{~B}$ & makes the receipt of a public service more efficient. & fewer steps have to be carried out by clients before the receipt of a service. \\
\hline & $1 \mathrm{C}$ & leads to an improved personalization of public services. & services relevant to each individual client are identified and delivered. \\
\hline & 1D & improves access to public organizations and their services. & no application is required for the receipt of a service. \\
\hline & $1 \mathrm{E}$ & leads to an improved inclusiveness of public services. & $\begin{array}{l}\text { all eligible clients receive a service; no eligible client is excluded because, for example, they are unaware of the } \\
\text { service. }\end{array}$ \\
\hline \multirow{5}{*}{$\begin{array}{l}\text { Improved } \\
\text { administrative } \\
\text { efficiency }\end{array}$} & $2 \mathrm{~A}$ & reduces costs for public organizations. & $\begin{array}{l}\text { there are fewer erroneous applications and fewer queries about forms; however, data must be obtained from sources } \\
\text { other than the clients. }\end{array}$ \\
\hline & $2 \mathrm{~B}$ & leads to reduced processing times in public organizations. & $\begin{array}{l}\text { although all clients potentially have to be checked for eligibility, better data quality and fewer queries can be } \\
\text { expected, and no application forms have to be checked. }\end{array}$ \\
\hline & $2 \mathrm{C}$ & reduces clients' waiting times for the receipt of services. & clients do not have to submit an application and, therefore, clients do not know when they should "start" to wait. \\
\hline & $2 \mathrm{D}$ & $\begin{array}{l}\text { comprises a suitable communication of public organizations" } \\
\text { decisions in public services. }\end{array}$ & $\begin{array}{l}\text { the communication of the result to the client is the only transmission of information between the public organization } \\
\text { and the client and, therefore, it is of high relevance for service design. }\end{array}$ \\
\hline & $2 \mathrm{E}$ & increases equal treatment and fairness. & all clients receive a service who are entitled to it, without having to do anything for it. \\
\hline \multirow{5}{*}{$\begin{array}{c}\text { Improved } \\
\text { ethical } \\
\text { behavior and } \\
\text { professionalism }\end{array}$} & $3 \mathrm{~A}$ & $\begin{array}{l}\text { better guarantees fundamental beliefs and constitutional } \\
\text { principles. }\end{array}$ & all clients are treated equally and receive the service without their intervention. \\
\hline & 3B & leads to a more appropriate and efficient use of public funds. & $\begin{array}{l}\text { public officials can focus on their core work and spend less time on avoidable tasks such as correcting incomplete or } \\
\text { inconsistent applications. }\end{array}$ \\
\hline & $3 \mathrm{C}$ & $\begin{array}{l}\text { leads to decisions being made more based on law and authorized } \\
\text { policy. }\end{array}$ & $\begin{array}{l}\text { the legislation is implemented consequently: if the legislature specifies a public service, then all clients receive the } \\
\text { service that are supposed to receive it according to law. }\end{array}$ \\
\hline & $3 \mathrm{D}$ & $\begin{array}{l}\text { might cause inconveniences and errors but these downsides are } \\
\text { tolerated. }\end{array}$ & $\begin{array}{l}\text { mistakes in proactive delivery are more serious because clients do not explicitly request a service (for example, } \\
\text { granting a service they do not want). }\end{array}$ \\
\hline & $3 \mathrm{E}$ & tortious interference and corruption are reduced. & automated systems can be used for proactive delivery, resulting in fewer decisions being made by humans. \\
\hline \multirow{5}{*}{$\begin{array}{l}\text { Improved trust } \\
\text { and confidence } \\
\text { in government }\end{array}$} & $4 \mathrm{~A}$ & $\begin{array}{l}\text { strengthens the awareness of clients that they will } \\
\text { services to which they are entitled. }\end{array}$ & all eligible clients are identified for a service using data analysis techniques and the service is provided to them. \\
\hline & \begin{tabular}{|l|l|l}
$4 \mathrm{~B}$ \\
\end{tabular} & preserves clients' control over their data. & comprehensive data analyses are performed to identify eligible clients and, there \\
\hline & $4 \mathrm{C}$ & $\begin{array}{l}\text { strengthens confidence in the capabilities of public } \\
\text { organizations. }\end{array}$ & $\begin{array}{l}\text { through the no-stop shop, public organizations demonstrate that they can overcome challenges and implement } \\
\text { innovative solutions. }\end{array}$ \\
\hline & $4 \mathrm{D}$ & $\begin{array}{l}\text { leads to a loss of control for clients over the receipt of public } \\
\text { services but the potential negative effects of this loss of control } \\
\text { are limited. }\end{array}$ & the no-stop shop could be perceived as dictation because a client is not asked for their consent to receive a service. \\
\hline & $4 \mathrm{E}$ & improves the adherence to democratic values. & all entitled clients receive a service, so that equal treatment, objectivity and fairness are strengthened. \\
\hline \multirow{5}{*}{$\begin{array}{l}\text { Improved } \\
\text { social value } \\
\text { and well-being }\end{array}$} & $5 \mathrm{~A}$ & improves the cohesion of society. & $\begin{array}{l}\text { equality among clients is strengthened; the receipt of a service is not attached to the conditions that a client knows a } \\
\text { service and is able to manage the application process. }\end{array}$ \\
\hline & $5 \mathrm{~B}$ & increases the satisfaction of clients. & $\begin{array}{l}\text { clients no longer have to do anything to obtain a public service; a public organization becomes inconspicuous and } \\
\text { clients can invest more time in other activities. }\end{array}$ \\
\hline & $5 \mathrm{C}$ & increases the clients' economic well-being and wealth. & $\begin{array}{l}\text { it reduces the communication between public organization and client to the transmission of the information about the } \\
\text { service receipt. }\end{array}$ \\
\hline & $5 \mathrm{D}$ & $\begin{array}{l}\text { leads to fewer social contacts to public officials but the } \\
\text { reduction in contacts has no negative impact on clients. }\end{array}$ & $\begin{array}{l}\text { there are fewer contacts with public officials. Some clients like to go to the city hall to apply for services in order to } \\
\text { interact with public officials, or choose a digital communication channel for interpersonal exchange. This is no longer } \\
\text { possible or necessary in a no-stop shop. }\end{array}$ \\
\hline & $5 \mathrm{E}$ & improves the positive impacts on nature and environment. & no paper applications are used and no drives to the city hall are necessary. \\
\hline
\end{tabular}




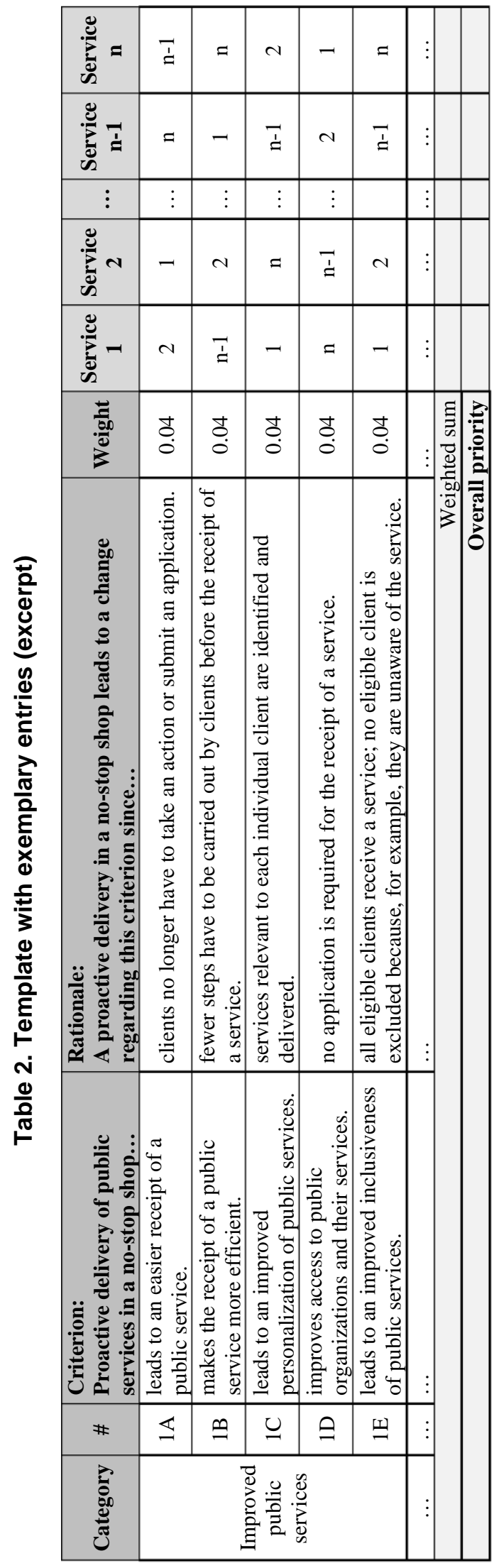

The first step is to identify potential services for an implementation in the no-stop shop. Here, public officials or external persons can suggest public services of which they think that a proactive provision is possible and useful. In carrying out this step, a focus can be given to a specific business area. Additionally, the suggested services need to be checked, whether they can be implemented in a no-stop shop at all by considering technical, legal or other implementation barriers.

The second step comprises making a shortlist of services. The aim of this step is to reduce the number of services to a manageable number, i.e. about five to seven, which are subsequently forwarded to step three for the actual assessment and prioritization. In this preselection, the practical feasibility must be considered above all. Not every public service can be delivered proactively in a no-stop shop or only with disproportionately high effort. A typical example is the civil marriage ceremony. The situation is similar to services where personal contact is beneficial or an essential part of the actual service, which might often be the case for social services.

The third step comprises the prioritization of the selected services using the catalog of criteria (cf. Table 1). The services are ranked in direct comparison to each other, since calculating a monetary value representing the benefit for each service would be too complex. The highest rank is represented by 1 . The highest rank is given to the service for which the expected added value of a proactive delivery in a nostop shop and related to the corresponding criterion is the highest. The rank " 1 " is given to the service for which the change towards proactive service delivery is the most positive, the rank " 2 " is given to the service with the second-best benefit, etc.

In this step, the number of cases of a certain service has to be considered. The benefit for the clients as a whole is considered and not for one client individually. If, for example, two services were ranked similarly due to their added value in individual cases, the service with the higher number of cases per year would also have a higher total benefit. In sum, the proactive delivery of the service with a higher number of cases has a stronger effect on the corresponding criterion.

This ranking is to be carried out for all 25 criteria so that a sum can be calculated for each service across all criteria. The lower this sum compared to that of other services, the higher is the corresponding service prioritized (cf. Table 2). This unweighted prioritization represents an initial recommendation as to which service is expected to have the greatest added value through proactive delivery.

Finally, in the fourth step, the different criteria are weighted. A weighting of individual criteria or categories enables to consider their possibly different 
relevance for clients and the public organization. For this purpose, the individual criteria or entire categories can be weighted within a range of 0 (no consideration of the criterion) to 1 (outstanding importance of the criterion). The sum of the weights of all 25 criteria should add up to 1 . This weighting should be determined through a negotiation or voting process within the group carrying out the method, which is an accepted instrument in public organizations [32]. The inclusion of different viewpoints is especially important in the public sector since various types of stakeholders and interconnected IT systems are affected or involved in service delivery processes. The negotiation process aims at balancing these different perspectives, but the individual arguments of course need to be reliable or fact-based so that the final result is traceable.

The weighting can be based, for example, on the strategic or political goals or the mission statement of a public organization. If, for example, the no-stop shop is primarily seen as a means of making administrative work more efficient, this would argue for a stronger weighting of the category "improved administrative efficiency". Once the weighting is done, the final prioritization of the services is available. The services with the highest priorities are recommended to be implemented in a no-stop shop at first.

\subsection{Example}

In the following, the method is illustrated by an example. In the first step, services A, B, C and D are assumed to be considered as potentially suitable for implementation in the no-stop shop. Due to their importance, only services A, B and C are shortlisted for implementation in the second step. In the third step, the services are ranked based on the individual criteria-excerpts for the category "improved public services" are shown in Table 3 (aspects addressed in the text are highlighted in grey in the table). Since a proactive delivery of service A entails the strongest simplification for clients compared to $\mathrm{B}$ and $\mathrm{C}$, it receives the highest rank for criterion $1 \mathrm{~A}$, which is marked by the assigned rank of " 1 ". During the weighting in the fourth step, a higher value is placed on criterion $1 \mathrm{D}$ and a lower value on $1 \mathrm{~B}$, so that the weights are increased to 0.05 and decreased to 0.03 respectively. So, in this example, "improves access to public organizations and their services"-criterion 1D-is considered more important than the other criteria. The weighted sum is obtained by multiplying weight and rank and then summing them up. This sum is lowest for service A (0.33), so this service is recommended to be implemented in the no-stop shop at first. This service is followed by service $\mathrm{C}(0.42)$ in second place and service $\mathrm{B}$ in third place $(0.45)$.
Table 3. Example of the presented method

\begin{tabular}{|c|c|c|c|c|c|}
\hline Categ & \# & Weight & $\begin{array}{c}\text { Service } \\
\text { A }\end{array}$ & $\begin{array}{c}\text { Service } \\
\text { B }\end{array}$ & $\begin{array}{c}\text { Service } \\
\mathrm{C}\end{array}$ \\
\hline \multirow{5}{*}{$\begin{array}{l}\text { Improved } \\
\text { public } \\
\text { services }\end{array}$} & $1 \mathrm{~A}$ & 0.04 & 1 & 2 & 3 \\
\hline & $1 \mathrm{~B}$ & 0.03 & 2 & 1 & 3 \\
\hline & $1 \mathrm{C}$ & 0.04 & 1 & 3 & 2 \\
\hline & $1 \mathrm{D}$ & 0.05 & 3 & 2 & 1 \\
\hline & $1 \mathrm{E}$ & 0.04 & 1 & 3 & 2 \\
\hline \multicolumn{3}{|c|}{ Weighted sum } & 0.33 & 0.45 & 0.42 \\
\hline \multicolumn{3}{|c|}{ Overall priority } & 1 & 3 & 2 \\
\hline
\end{tabular}

\section{Evaluation}

The method was applied and tested in a workshop at a municipality. After a thematic introduction, the practical testing of the method started with the identification of potential services for a no-stop shop (step 1). The participants were asked to identify suitable services and to explain them. In view of the further course of the workshop, the selection of services was limited to the expertise of the participants. Nevertheless, it became apparent that from the point of view of the public officials, a large number of services is potentially suitable for a no-stop shop. The participants identified 24 services or service bundles as potentially suitable for implementation in a no-stop shop.

In the subsequent discussion (step 2), the following five services or service bundles emerged as particularly suitable, were shortlisted for detailed assessment and specified as follows (some of these services require legislative changes for implementation in a no-stop shop, but were classified as easily implementable from a processual point of view):

- Initial (financial) support in case of pregnancy (SGB II-German law for unemployment benefits): These are additional monetary and non-monetary benefits that are paid to unemployed clients in case of pregnancy and/or birth.

- Assistance for the waiver to pay broadcasting fees: This involves support from the public organization when applying for exemption from the obligation to pay broadcasting fees. The exemption itself can only be made by the organization that is responsible for the broadcasting fees.

- Asylum (AsylBLG-German law for granting asylum): Service to grant asylum for persons who have already been registered elsewhere in Germany for the first time.

- Communal family passport: This is a pass that grants certain benefits to families in this municipality. 
- Old-age benefit (SGB XII-German law for old-age benefits including cases of reduced earning capacity): First application for the monetary service for elderly people if benefits have already been received in accordance with SGB II or SGB XII before. The focus is given to the transition to a new legal basis for the payments that applies with reaching a certain age.

The subsequent prioritization of the services based on the catalog of criteria revealed a surprising picture (step 3). Four of the five services received the same number of points so that there were still no clear indications for a prioritized order for implementation (cf. Table 4).

Only due to the subsequent weighting of the criteria a clear result could be achieved (step 4). The participating public officials assigned a higher weight of 0.3 (0.06 for each criterion) to the category "improved administrative efficiency" and the category "improved ethical behavior and professionalism" received a lower weight of 0.1 (0.02 for each criterion). They made this decision since, with regard to the improvement of internal processes, it was argued that in addition to the public organization, "the citizens will definitely also benefit if everything runs faster and better in our administration because then tax money is also saved".

\section{Table 4. Results from the exemplary application of the method}

\begin{tabular}{|l|l|l|}
\hline Service & $\begin{array}{l}\text { Priority } \\
\text { with } \\
\text { weighting }\end{array}$ & $\begin{array}{l}\text { Priority } \\
\text { without } \\
\text { weighting }\end{array}$ \\
\hline Communal family passport & 1 & 1 \\
\hline $\begin{array}{l}\text { Assistance for the waiver to } \\
\text { pay broadcasting fees }\end{array}$ & 2 & 1 \\
\hline $\begin{array}{l}\text { Initial (financial) support in } \\
\text { case of pregnancy }\end{array}$ & 3 & 1 \\
\hline Old-age benefit & 4 & 1 \\
\hline Asylum & 5 & 5 \\
\hline
\end{tabular}

The assessment of the method by the workshop participants was generally positive. They emphasized the usefulness of the method and the consideration of all relevant factors that influence the public organization and clients in proactive service delivery. Nevertheless, some criteria were formulated in a too abstract way and were not immediately comprehensible. Based on this feedback, we made some adaptions. On the one hand, the corresponding criteria were formulated more precisely and put in a different order, and on the other hand, explanations were added to all criteria to ensure a uniform understanding (cf. rationales in Table 1 and Table 2). In particular, the changed order is intended to facilitate an introduction to the topic.
The application of our method showed that the possibility of assigning different weights to the categories or criteria is important. This makes it possible to set organization-specific priorities. Furthermore, it became clear during the workshop that by using the method to select services, the influence of personal preferences or arbitrary decisions about prioritizing services for implementation in the no-stop shop can be reduced. The participants were surprised about the final order of services, as they would have come to a different result without the application of the criteria or on the basis of their own personal subjective assessment.

\section{Discussion and Conclusion}

In this paper, we propose a method for the prioritization of public services for implementation in a no-stop shop. Relying on the public value concept, our method takes into account different stakeholders of digital government such as clients, public organizations and the entire society. To account for the strategy and aims of an individual public organization, weights can be assigned to each criterion, for instance, if organizations value the benefits for clients higher than the internal benefits for the organization itself. The criteria are relevant to no-stop shops and take into account their specifics. The method is not dedicated to an individual organization but is intended to be applicable by public organizations in general.

Our paper provides implications for researchers and practitioners. Practitioners can apply our method to determine the services that are to be implemented in a no-stop shop in their organizations first. Although the first step of our method is preparatory, it is crucial for a successful application of our method, since it is important to think about which services could be offered in a no-stop shop at all. Such considerations should cover especially legal (which services are we allowed to provide without the client's consent?) and technical questions (are we able to technically integrate all necessary data?). These services that could be potentially delivered in a no-stop shop build the foundation for our method. When evaluating such services with our method, employees from various departments should bring in their expertise. Our method requires detailed knowledge about each service and most probably the services originate from various business areas so that employees from all affected departments should be involved in the application of our method.

Practitioners might not only apply our criteria ex ante but also ex-post. They can use our criteria also to evaluate the success of a completed no-stop shop implementation. Practitioners can define goals for each criterion in their organizations. Once the public 
organization has used the implementation in service delivery for a while, they can determine to what extent they have achieved their goals through the no-stop shop by, for instance, calculating the internal cost savings and asking clients for their level of satisfaction.

Researchers can transfer the idea of our methodassessing the expected impact of different alternatives on public value-to other decisions such as digitalization decisions in public organizations in general. Researchers could develop methods with which to decide which services are to be transferred from analogous to digital processing first. Services could be assessed with criteria similar to ours to come to a decision. Our method makes use of both KPIs and negotiations. Decision-making in the public sector is oftentimes complex due to the involvement of several stakeholders. This leads to frequent use of negotiations [32] instead of a more objective application of performance indicators as the basis for decision-making [29]. However, both mechanisms are important in the public sector. Therefore, on the one hand, our method explicitly includes operationalizable indicators when comparing the expected value of the implementation of different services in a no-stop shop. On the other hand, the method requires negotiations when deciding about the ranking and the weights, i.e. importance, of different criteria or categories ensuring a balanced decision.

The criteria and their rationales also help researchers to conceptually understand the potential impact of the no-stop shop on public value. For instance, a no-stop shop could reduce the clients' waiting times, increase their confidence in the capabilities of public organizations and improve the cohesion of society. This understanding helps researchers in their future research on the no-stop shop phenomenon as they have more knowledge about the no-stop shop's relationship to a fundamental concept in the literature-public value.

Our work is also subject to limitations and future research. Scholars can investigate the application of our method in public organizations to evaluate the usefulness of our method in practice. Our evaluation provides first insights that indicate the method's usefulness but it can be extended by a more comprehensive evaluation in practice. In the future, researchers can extend and develop our method further. New developments and insights on the no-stop shop might appear over time and might need to be incorporated into our method.

Despite these limitations, we believe that our method is a valuable tool that assists public organizations in the selection of services for a no-stop shop-a topic that will increasingly change public service delivery.

\section{References}

[1] I. Mergel, N. Edelmann, and N. Haug, "Defining digital transformation: Results from expert interviews," Gov. Inf. Q., vol. 36, no. 4, 2019.

[2] United Nations, "E-Government Survey 2020: Digital Government in the Decade of Action for Sustainable Development," 2020. [Online]. Available:

https://publicadministration.un.org/egovkb/Portals/e govkb/Documents/un/2020-Survey/2020 UN EGovernment Survey (Full Report).pdf. [Accessed: 15-Jun-2021].

[3] H. Scholta, W. Mertens, M. Kowalkiewicz, and J. Becker, "From one-stop shop to no-stop shop: An egovernment stage model," Gov. Inf. Q., vol. 36, no. 1, pp. 11-26, 2019.

[4] J. Bosse, M. Burnett, S. Møller Nielsen, C. Rongione, and H. Scholtens, European Public Sector Award 2015: The Public Sector as Partner for a Better Society. Maastricht: European Institute of Public Administration, 2015.

[5] K. K. Larsson, "Digitization or equality: When government automation covers some, but not all citizens," Gov. Inf. Q., vol. 38, no. 1, pp. 1-10, 2021.

[6] D. Boost, P. Raeymaeckers, K. Hermans, and S. Elloukmani, "Overcoming non-take-up of rights: A realist evaluation of Integrated Rights-Practices," $J$. Soc. Work (Online First), 2020.

[7] H. Scholta and I. Lindgren, "The Long and Winding Road of Digital Public Services-One Next Step: Proactivity," in Proceedings of the 40th International Conference on Information Systems (ICIS 2019), 2019.

[8] M. Moore, "Creating Public Value: Strategic Management in Government." Harvard University Press, Cambridge, London, 1995.

[9] M. H. Moore, "Public Value as the Focus of Strategy," Aust. J. Public Adm., vol. 53, no. 3, pp. 296-303, 1994.

[10] J. D. Twizeyimana and A. Andersson, "The public value of E-Government - A literature review," Gov. Inf. Q., vol. 36, no. 2, pp. 167-178, 2019.

[11] D. Linders, C. Z.-P. Liao, and C.-M. Wang, "Proactive e-Governance: Flipping the service delivery model from pull to push in Taiwan," Gov. Inf. Q., vol. 35, no. 4, pp. S68-S76, 2018.

[12] M. Brüggemeier, "Auf dem Weg zur No-StopVerwaltung," Verwaltung Manag., vol. 16, no. 2, pp. 93-101, 2010.

[13] B. Klievink and M. Janssen, "Realizing joined-up government - Dynamic capabilities and stage models for transformation," Gov. Inf. Q., vol. 26, no. 2, pp. 275-284, 2009.

[14] J. K. Kampen and K. Snijkers, "E-Democracy: A Critical Evaluation of the Ultimate E-Dream," Soc. Sci. Comput. Rev., vol. 21, no. 4, pp. 491-496, 2003.

[15] A. Bichler-Wagner, W. Katzmann, M. Plank, and R. Zettinig, "Granting Family allowance without application - 'ALF,", Federal Ministry of Finance, 2015. [Online]. Available: 
http://www.epsa2015.eu/files/ALF_AT.pdf. [Accessed: 11-Oct-2016].

[16] R. Krimmer, T. Kalvet, M. Toots, A. Cepilovs, and E. Tambouris, "Exploring and Demonstrating the Once-Only Principle: A European Perspective," in Proceedings of the 18th Annual International Conference on Digital Government Research (dg.o '17), 2017, pp. 546-551.

[17] M. A. Wimmer, E. Tambouris, R. Krimmer, J. R. GilGarcia, and A. T. Chatfield, "Once Only Principle: Benefits, Barriers and Next Steps," in Proceedings of the 18th Annual International Conference on Digital Government Research (dg.o '17), 2017, pp. 602-603.

[18] R. Erlenheim, D. Draheim, and K. Taveter, "Identifying design principles for proactive services through systematically understanding the reactivityproactivity spectrum," in Proceedings of the 13th International Conference on Theory and Practice of Electronic Governance (ICEGOV 2020), 2020, pp. 452-458.

[19] H. Kõrge, R. Erlenheim, and D. Draheim, "Designing Proactive Business Event Services: A Case Study of the Estonian Company Registration Portal," in Proceedings of the International Conference on Electronic Participation (ePart 2019), 2019, pp. 73 84.

[20] P. Kuhn and D. Balta, "Service Quality Through Government Proactivity: The Concept of Noninteraction," in Proceedings of the International Conference on Electronic Government (EGOV 2020), 2020, pp. 82-95.

[21] P. Kuhn, D. Balta, and H. Krcmar, "Was sind Herausforderungen proaktiver Verwaltungsleistungen in Deutschland?," in Proceedings of the 15th International Conference on Wirtschaftsinformatik (WI2020), 2020, pp. 554-559.

[22] J. O'Flynn, "From new public management to public value: Paradigmatic change and managerial implications," Aust. J. Public Adm., vol. 66, no. 3, pp. 353-366, 2007.

[23] A. Cordella and C. M. Bonina, "A public value perspective for ICT enabled public sector reforms: A theoretical reflection," Gov. Inf. $Q$., vol. 29, no. 4, pp. 512-520, 2012.

[24] M. Scott, W. H. DeLone, and W. Golden, "Understanding Net Benefits: A Citizen-Based Perspective on eGovernment Success," in Proceedings of the 30th International Conference on Information Systems (ICIS 2009), 2009.

[25] L. Dadayan, "Measuring return on government IT investments," in Proceedings of the 13th European Conference on Information Technology Evaluation, 2006.

[26] A. M. Chircu, "E-government evaluation: towards a multidimensional framework," Electron. Gov. an Int. J., vol. 5, no. 4, pp. 345-363, 2008.

[27] F. Bannister and R. Connolly, "ICT, public values and transformative government: A framework and programme for research," Gov. Inf. Q., vol. 31, no. 1, pp. 119-128, 2014.

[28] M. Scott, W. Delone, and W. Golden, "Measuring
eGovernment success: A public value approach," Eur. J. Inf. Syst., vol. 25, no. 3, pp. 187-208, 2016.

[29] J. Taylor, "Strengthening the link between performance measurement and decision making," Public Adm., vol. 87, no. 4, pp. 853-871, 2009.

[30] A. R. Hevner, S. T. March, J. Park, and S. Ram, "Design Science in Information Systems Research," MIS Q., vol. 28, no. 1, pp. 75-105, 2004.

[31] H. Österle et al., "Memorandum on design-oriented information systems research," Eur. J. Inf. Syst., vol. 20, no. 1, pp. 7-10, 2011.

[32] P. C. Nutt, "Comparing public and private sector decision-making practices," J. Public Adm. Res. Theory, vol. 16, no. 2, pp. 289-318, 2006. 